\title{
Dear deer? Maybe for now. People's perception on red deer (Cervus
}

\section{elaphus) populations in Portugal}

Ana M. Valente ${ }^{\mathrm{a}, \mathrm{b}^{*}}$, Pelayo Acevedo $^{\mathrm{b}}$, Ana M. Figueiredo ${ }^{\mathrm{a}, \mathrm{c}}$, Raquel Martins ${ }^{\mathrm{a}}$, Carlos Fonseca $^{\text {a }}$, Rita T. Torres ${ }^{\mathrm{a}}$, Miguel Delibes-Mateos ${ }^{\mathrm{d}}$

${ }^{a}$ Departamento de Biologia e CESAM, Universidade de Aveiro, Campus Universitário de Santiago, 3810-193 Aveiro, Portugal.anamvalente@ua.pt; anamfigueiredo@ua.pt; raquel.sofia@ua.pt; cfonseca@ua.pt; rita.torres@ua.pt.

${ }^{b}$ Instituto de Investigación en Recursos Cinegéticos (UCLM-CSIC-JCCM), Ronda de Toledo 12, 13071 Ciudad Real, Spain.pelayo.acevedo@uclm.es.

${ }^{c}$ Department of Bioscience \& CEES, University of Oslo. Blindernvn. 31, 0371, Oslo, Norway.

${ }^{d}$ Instituto de Estudios Sociales Avanzados, IESA-CSIC, Campo Santo de los Mártires 7 , 14004, Córdoba, Spain,mdelibes@iesa.csic.es.

*Corresponding author: anamvalente@ua.pt 


\section{Abstract}

5 Human dimension of wildlife is a subject of increasingly interest, especially considering

6 the potential impact of people's perception on decision-making regarding wildlife

7 management and thus on species distribution and abundance. This is particularly

8 important for species that inhabit human-dominated landscapes, where conflicts over

9 wildlife management are likely to arise. These conflicts typically emerge between different collectives when their interests collide and thus their perception is valuable. Throughout Europe, ungulates have expanded in number and distribution area, and Portugal is no exception. The expansion of red deer (Cervus elaphus) comes with benefits (e.g. hunting opportunities), but also with costs (e.g. vehicle collision or damage to crops), which can shape people's opinion. To assess perception of red deer populations in continental Portugal, we developed a questionnaire survey with three main interest groups: general public, farmers and hunters (total $n=1532$ ). Our results show that perception of red deer was generally positive with a high acknowledgement of deer benefits, which we link to a broad level of sympathy towards this species. In addition, we found that farmers showed a higher perception of crop damage caused by deer than nonfarmers. Nonetheless, a general lack of knowledge regarding wildlife was present, particularly in younger people, which are potentially more apart and disconnected from nature. Now is the time to implement preventive and mitigation measures - e.g. fencing of agricultural fields, reduction of population density in some areas - which can avoid Portugal to be the next example of red deer overabundance. For that, evaluation of people's attitudes and awareness towards the acceptance of the needed strategies (sometimes unpopular) are essential. People's opinion, as well as the success of monitoring strategies, should be evaluated through multi-disciplinary teams, that include both natural and social scientists, to ensure its success. 
29 Keywords: attitudes, enquiries, human dimension, wildlife, Portugal, questionnaire survey

\section{Introduction}

The study of human dimension of wildlife in conservation and management projects has increased in recent years, and it is particularly important for wildlife species that inhabit human-dominated landscapes (Behr et al. 2017). How people view and position towards wildlife species usually influences their management, thus potentially shaping species distribution and abundance (Mech 1995; Chapron et al. 2014). For example, there is broad social acceptability of lethal management of some wildlife species like rodents, which are widely controlled often with public funds. By contrast, large predators exert fascination on the general public, which makes their control usually unpopular (Delibes-Mateos 2015), and it is thus more rarely carried out. Indeed, towards the same hypothetical damages, people's perception changes depending on species, as so their leaning in accepting some needed management measures (Wittmann et al. 1998; Garrido et al. 2017). This means that, to be efficient, wildlife management requires an integrated approach that involves both the ecological, human and socio-economic dimensions (Behr et al. 2017). In fact, humans are an integral part of the ecosystem thus, their attitudes and perception towards wildlife populations must be analyzed and discussed in order to apply socially acceptable management actions (Røskaft et al. 2007).

The study of human dimension of wildlife is particularly relevant in the context of the socalled "human-wildlife conflicts". Traditionally, most of the human-wildlife conflict studies addressed wildlife impacts on human livelihood or safety or impacts of human activities on the needs of wildlife (Madden 2004; Peterson et al. 2010). However, it is increasingly acknowledged that those conflicts emerge between humans with different 
interests over wildlife species, different understanding of wildlife management and contrasting perspectives on how to address wildlife threats to human interests, or even on how to manage impacts of human activities on wildlife through hunting, urbanization, landscape fragmentation, among others (Marshall et al. 2007; Redpath et al. 2013; Storie et al. 2017). This dual vision about conflicts (Kansky et al. 2016), replaces which can be seen as a human-wildlife conflict into a human-human one, and also affects the way that management issues are tackled, stressing out the relevance of understanding the views and attitudes of people towards wildlife and their management. For example, hunters and farmers portray different ideal density thresholds for game species that cause damage crops like ungulates (e.g. Storie et al. 2017).

In the past few decades, ungulates have grown both in number and distribution area across Europe (Apollonio et al. 2010). This growth brought up consequences that requires diagnose and quantification in order to implement proper cost and time effective silviculture (Reimoser and Reimoser 2010); increase in infectious diseases that affect ungulate-vehicle collisions (Marques et al. 2010; Mysterud 2004); impacts on natural vegetation (Perea et al. 2014) and even the decrease in other wildlife species density (mainly caused by the effects on the woodland), such as birds (Newson et al. 2012), invertebrates (Gobbi et al. 2018) or even small mammal species (Dolman et al. 2010), are only some examples of the impact caused by the increase of ungulates. The admissible levels of density depend on the ecological and socio-economic scenario in which the population is located which is also determinant to design management strategies (Carpio 
complex task, which is also influenced by the fact that mitigation strategies are often costly and/or ineffective (but see Barasona et al. 2013) and that lethal management cause often strong social opposition (Garrido et al. 2017). In addition, the management of ungulate impacts is at the root of conflicts between collectives like hunters, farmers or conservationists (Delibes-Mateos 2015). In this context, it is essential to understand how both the general public and the groups involved in ungulate management perceive these species, their impact on ecosystems and human activities as well as their management (see e.g. Pascual-Rico et al. 2020).

Red deer (Cervus elaphus) is one of the most broadly distributed ungulate species in Europe and their negative impacts are fully addressed (Côté et al. 2004; Valente et al. 2020), as well as the conflicts arise by their consequences (e.g. MacMillan and Leitch 2008; Martin et al. 2020). In Portugal, as occurs along Europe, this species has expanded both in number and distribution, due to natural dispersion processes and reintroductions (Vingada et al. 2010; Carvalho et al. 2018). Effective management of deer populations requires social acceptance of management programs and particularly of techniques employed to locally reduce deer numbers (Martínez-Jauregui et al. 2020). In this sense, understanding people's perception of deer and their damage is crucial to design socially acceptable management strategies.

The urgency to assess simultaneously attitudes of general public and different collectives towards deer and their management and the inexistence of any study in Portugal regarding this subject brings up a novelty to this research field. This study aims to: (1) assess people's interest for wildlife and particularly their attitudes toward red deer populations in Portugal - predicting a general negative attitude toward deer because their increase may cause detrimental effects on human livelihood and safety (see above); (2) investigate perceived benefits and costs associated with deer; 3) assess how perceptions vary in 
function of socio-demographic variables. For example, we predicted that people with more knowledge and experience on red deer would have higher interest in wildlife (and deer in particular), as well as would identify more often costs and benefits associated with deer; and (4) assess differences in perceptions between general public, hunters and farmers - predicting, for example, a higher perception of deer damages in the more affected collectives (i.e. farmers) and a higher interest in wildlife among people in closer contact with nature (i.e. hunters).

\section{Material and Methods}

\subsection{Questionnaire design}

The questionnaire had three well differentiated parts. The first block of questions addressed respondents' experience with and knowledge of red deer. For example, we asked if they had seen deer and with which frequency; we also inquired about their perception of deer population trends in the last five years - from a greatly decrease to a greatly increase (Appendix A). The second part of the questionnaire dealt with attitudes towards deer and perceptions of their potential costs and benefits. We also asked here about deer management goals (to decrease, stabilize or increase deer populations). We mostly used Likert-scale questions in this section (Appendix A); a 5-points scale was used in which 1 meant strongly disagreed and 5 strongly agreed. We asked respondents to classify, for example, if "See a deer in the nature would be a pleasant experience", if "Deer constitute a problem for being associated with car accidents", or if "Deer produce a positive economic impact through hunting". This section enabled us to perform three indexes related to interest for wildlife, perceived deer damage and perceived deer benefits perception, which we deepen below. The last part of the questionnaire aimed to gather 
127 sociodemographic information about the respondents, such as age group, academic

128 qualifications, or the interest group where people are inserted (hunters, primary farmers,

129 secondary farmers or general public).

\subsection{Survey implementation}

Two strategies were used to recruit participants for the study. First, paper copies of the questionnaire were distributed between November 2017 and September 2018 in the municipalities of Bragança, Castelo Branco, Idanha-a-Nova, Lousã, Penela and Castanheira de Perâ, since they represent the main nucleus of red deer in Portugal (Montesinho mountains, Lousã Mountains and Beira Baixa). The questionnaires were self-administered and distributed through these municipalities, in strategic points like coffees, associations, stores, etc., where we expected to encounter our interest groups. We specifically target hunting and farming associations because we were particularly interested in assessing the opinion of those collectives. Complementarily, we conducted an online questionnaire survey between November 2018 and March 2019 using the Google Forms tool. All municipalities of continental Portugal were invited to collaborate with our study, as well as some associations (mainly hunting and farming related associations) that could be related with this thematic. Contacts were made via e-mail with a description of our work and the URL to our online survey to publicize among citizens/associates. The online survey was also promoted through social networks, namely Facebook, with a personal profile and the spread through groups gathering either

147 hunters, farmers and general public of continental Portugal. Based on the received responses, farmers were then divided into primary farmers, which have agriculture as the main source of income, and secondary farmers, which have agriculture as a secondary source of income (Table 1). 
152

153

154

155

156

157

158

159

160

161

162

163

164

165

166

167

168

169

170

171

172

173

174

175

To ensure an easier (and still robust) data interpretation, some key questions were grouped into three indexes (using the mean of the chosen responses) that represented participants' interest for wildlife (questions 2, 3 and 4 of the second section of the questionnaire; Appendix A), their perception of damages caused by deer (questions 5, 6, 7, 8, 9 and 14 of the second section of que questionnaire) and perceived deer benefits (questions 10, 11, 12 and 13 of the second part of the questionnaire). The three questions analyzed further that were not included in the Likert scale, have their own interpretable degree (i.e. in sighting frequency it begins with "never saw" until it reaches "weekly sightings"; in deer tendency in the last years it goes from "greatly decreased" until it reaches "greatly increased"; in deer management goals it goes from a "decrease" to "stabilize" and "increase"; for analysis purposes we have eliminated the responses of people who said "do not know" or "do not answered" - $0.6 \%, 51,6 \%$ and 28,4\% respectively).

Generalized linear models (GLM) with a Poisson distribution and a logarithmic link were carried out to analyse the relationship between the deer sighting frequency, the perception on deer tendency over the last five years, the opinion on how to manage deer populations, the interest in wildlife, perceived deer costs and benefits (six questions were used as response variable) and sociodemographic data (see Table 1) as explanatory variables. Then, a stepwise backwards elimination (through AIC values) was performed to get the final models and assess the significant differences through drop chi-square tests. Lastly, a post-hoc test was performed, through Tukey HSD (Honestly Significant Difference) to assess detailed and significant differences among the categories within each variable (confidence level $=95 \%$ ). For this purpose, RStudio (RStudio Team 2015) was used, along with R packages "MASS" (Venables and Ripley 2002) and "effects" (Fox and Weisberg 2019) for plotting the results. 
176 Additionally, with an exploratory purpose, GLM analyses were carried out independently

177 for paper and online version of the survey to assess if any contradictions were present 178 (due to different survey methodology), although our results always refer to the global data 179 set. When describing the results, we mean that non-hunters is constituted by general 180 public and farmers who did not hunt; and non-farmers by general public and hunters who 181 were not also farmers.

\section{Results}

\subsection{Survey respondent's}

In total, 1532 people participated in our survey: 1219 answered the online version of the questionnaire and 313 the paper copy (Figure 1). There were more men than women among respondents, and predominated intermediated age-classes and people with high academic qualifications (Table 1 and Appendix B). The participation of older people and those with no studies or studies of first cycle was very low in the online survey but was a little higher in the paper version. Men represented $70.6 \%$ of the responders and women 29.4\%. Regarding age, individuals below 30 years represented $21 \%$; individuals between 30 and 45 years represented 31.3\%; individuals between 45 and 60 years represented 29.6\%; individuals between 60 and 75 represented $15.5 \%$; and individuals with more than 75 years represented $2.6 \%$. We have sampled $>35 \%$ hunters, and about half $(\sim 50 \%)$ farmers (but only $18 \%$ as a principal source of income), that can potentially bias our estimates, which we discuss later.

3.2 Experience with and knowledge of deer, and attitudes towards deer and their management 
Most people had never seen or just rarely see red deer (Figure 2, 25.9\% and 45.4\% respectively). $13.4 \%$ reported to see deer every three months, while $11.4 \%$ and $3.3 \%$ reported a monthly and weekly deer sight, respectively. Older people had seen deer more frequently than younger ones (e.g. $>75$ years $v s<30$ years- diff: 0.84 , p-value $<0.001$; $>75$ years $v s$ 30-45 years - diff: 0.55 , p-value $=0.006$ ), as well as men in relation to women (diff: 0.38, p-value <0.001). People with higher academic qualifications had seen deer less frequently (e.g. college $v s 2^{\text {nd }}$ cycle - diff: -0.48 , p-value $=0.001$; college $v s 3^{\text {rd }}$ cycle - diff: -0.51, p-value $<0.001)$. Primary and secondary farmers had seen deer more frequently than non-farmers as well as hunters in relation to non-hunters (diff: 0.31 , pvalue $<0.001$; diff: 0.21 , p-value $=0.001$; diff: 0.36 , p-value $<0.001$ respectively)

Most people did not record any opinion on red deer tendency in the last years $(51,6 \%)$. From the respondents, $10 \%$ and $20.1 \%$ of them believe that red deer populations are greatly increasing or increasing, respectively. $10.5 \%$ of the respondents think that red deer populations are stable. $4.5 \%$ and $3.3 \%$ of them think that deer populations are decreasing or greatly decreasing, respectively. Significant differences were registered among age classes, with older people thinking more frequently that deer populations are increasing (e.g. $>75$ years $v s<30$ years - diff: -0.85 , p-value $=0.002 ; 60-75$ years $v s<30$ years diff: $-0.80, p$-value $<0.001$ ) as well as men in relation to women (diff: -0.26 , p-value $=$ 0.01). We did not find significant differences among interest groups in this question (Figure 2).

Most people want that deer management goal be the stabilization of these wild populations (31.1\%). $28.4 \%$ did not answered this question and $27 \%$ want their increase while $13.3 \%$ want their decrease. Significant differences were found involving age classes and farmers vs non-farmers (Figure 2). Older people seemed to agree that deer management should seek population decrease or stabilization in opposition to younger 
ones (e.g. 60-75 years $v s<30$ years - diff: 0.55 , p-value $<0.001 ; 60-75$ years $v s$ 30-45 years - diff: $0.30, \mathrm{p}$-value $=0.002$ ). Primary and secondary farmers also agreed with a population decrease or stabilization in opposition to non-farmers (diff: 0.38 , p-value $<0.001$; diff: 0.20 , p-value $=0.005$ respectively). Academic qualifications, gender and hunting did not reveal significant interactions.

229 For final GLM models information see table 2.

Patterns obtained in the online and paper surveys coincided, although results were not always significant when analyzed separately (particularly for the paper version, which presents a lower number of responders). For more details see Appendix C.

\subsection{Interest for wildlife}

234 Attitude towards wildlife was in general positive throughout the sampled people (Figure 3). This index revealed different age patterns, with younger people presenting higher scores (e.g. $>75$ years $v s<30$ years - diff: -91.34 , p-value: $<0.001$ or $60-75$ years $v s<30$ years - diff: -47.46 , p-value: <0.001). Academic qualifications did not evidence any clear pattern, except for the difference between people with college studies and those who attended high school (diff: 24.42, p-value: <0.001). Attitude towards wildlife of primary farmers was significantly more negative than that of non-farmers (diff: -38.82 , p-value: $<0.001)$. Secondary farmers' attitudes towards wildlife was more positive than that of primary farmers (diff: 20.95, p-value: 0.03 ). Hunters had a more positive attitude towards wildlife than non-hunters (diff: 20.03, p-value <0.001).

\subsection{Perceived deer costs}

Damage perception was highly variable among groups, but deer damage was usually recognized (generally $>2.5$ in Likert scale - Figure 3). Damage perception index increased with age (e.g. $>75$ years $v s<30$ years - diff: 89.45 , p-value $<0.001$; $>75$ years 
vs 30-45 years - diff: 73.28, p-value <0.001), and decreased, normally, with academic qualifications (e.g. college vs. $1^{\text {st }}$ cycle - diff: -37.36 , p-value $\left.<0.01\right)$. Primary and secondary farmers showed higher damage perception than non-farmers (diff: 60.39, pvalue $<0.001$ and diff: 29 , p-value $<0.001$ respectively), being primary farmers the ones who perceived higher costs associated with deer (secondary farmers $v s$ primary farmers - diff: -31.4, p-value <0.001). Hunters had a higher damage perception than non-hunters (diff: 23.03, p-value <0.001).

\subsection{Perceived deer benefits}

In general, the sampled people recognized the benefits of red deer in Portugal (Figure 3).

Male respondents had higher scores of the deer benefits index (diff: 22.6, p-value $<0.001$ ).

Perceived deer benefits decreased with age (e.g. $>75$ years $v s>30$ years - diff: -65.5 , pvalue $<0.001$ or $>75$ years vs $30-45$ years - diff: -63.66 , p-value $<0.001)$ and increased with academic qualifications (e.g. college $v s 1^{\text {st }}$ cycle - diff: 35.51 , p-value: 0.008 or college $v s$ high school - diff: 25.3, p-value $<0.001)$. Primary and secondary farmers tended to associate less benefits with deer (diff: -22.35 , p-value: 0.001 and diff: -17.36 , p-value: 0.003 respectively). Hunters had higher scores of the index than non-hunters (diff: 25.94 , p-value $<0.001$ ).

\section{Discussion}

In general, results show that many people in Portugal view deer more positively than one would expect with a perception on deer associated benefits generally greater than the perceived costs. In addition, a great proportion of people believed that deer numbers should be increased, and this was particularly evident among younger people in the 
272 (acknowledge in several studies - Ballantyne 2012; Noren 2018; Martin et al. 2020, but 273 see Pascual-Rico et al. 2019) is the fact that deer is seen as a mystic animal throughout 274 time, enhanced by several movies, in which this species is a beloved character. People base their perceptions not only upon facts and personal experiences, but also upon societal experiences and cultural norms, among others (Dickman 2010). There are clearly popular

277 and unpopular animals (Driscoll 1995), and our results support that deer would be among the former. This is striking giving deer increase and associated impacts all over Europe (Valente et al. 2020), including Portuguese mountains, where deer expansion caused habitat degradation and increasing conflicts (e.g. Carvalho and Frazão-Moreira 2011; Monzón et al. 2012). Nevertheless, deer are not overabundant in Portugal yet (Torres et al. 2015; Valente et al. 2017), which could explain that deer costs were identified less frequently than their benefits.

4.1 Experience with and knowledge of deer, and attitudes towards deer and their management

Most people did not know the increase in deer numbers in the last years, revealing a lack of general knowledge regarding wildlife. This lack of knowledge was particularly obvious among younger individuals, who are probably more apart from nature (see e.g. Soga and Gaston 2016). This deserves a deeper analysis and can be a result of the increasingly disconnection between people and nature (Turner et al. 2004; Soga and Gaston 2016), which is likely linked with rural exodus that have also contributed to deer augment. The fact that increasing deer's population was perceived mostly by older people, hunters and farmers suggests that they potentially present a higher bond with nature, which is also reinforced by their generally higher (when in comparison with others) deer sighting frequency. 
297

298

299

300

301

302

303

304

305

306

307

308

309

310

311

312

313

314

315

316

317

\subsection{Sociodemographic features}

Age patterns found in all indexes are corroborated by other studies (Bjerke et al. 1998 in Williams 2002; Williams et al. 2002). When analyzing age and academic qualification patterns we can assess that older people ( $>75$ years) were the ones with less academic qualifications (illiterate or $1^{\text {st }}$ cycle) and the ones having agriculture as a source of income, which can explain some of the features found (see Appendix B for detailed demographic data). Contrastingly, as happen in Liu et al. (2011), people with more contact with deer showed the most negative attitudes (e.g. elder people). In general, respondents with higher academic qualifications were the most interested in wildlife, perceived more frequently benefits associated with deer and had a lower perception of deer costs. In fact, this was also found before (Williams et al. 2002), as it can also be related with less unpleasant personal experiences regarding this species (Dickman and Hazzah 2015), also linked to the interest groups analysis performed below. In addition, this could be connected to a greater awareness of wildlife and environment thought in schools and universities but can also be associated with other personal features (e.g. sensibility, empathy, cultural inheritance), that influence general perception.

\subsection{Interest groups}

Farmers showed less interest in wildlife and perceived deer damage often but did not identify deer benefits as frequent as other groups. This can be explained by economic losses they experience due to ungulates damage, which can constrain respondents' opinion not only about the damaging species but also about wildlife in general (Williams et al. 2002; Kansky et al. 2014). Actually, this is supported by a decreasing gradient of perceived deer costs (primary farmers/secondary farmers/non-farmers) identified in our 
analyses, and it is in agreement with previous studies that showed that tolerance to ungulate damage is proportional to the probability of experiencing damage (Kansky et al. 2014; Dickman and Hazzah 2015). Similarly, Lischka et al. (2008) observed that acceptance for certain deer densities were most influenced by the perceived impact of species, which can be exacerbated by the ones experiencing damage like farmers.

Hunters had a greater interest in wildlife, more positive attitudes towards deer, and showed a greater perception of deer benefits than non-hunters. This is not surprising as game species are the basis of their recreational activity (see e.g. Kellert 1983; DelibesMateos 2015; Martin et al. 2020), At the same time, hunters also presented a greater perception of damage caused by deer, revealing a deeper knowledge about deer populations. Martin et al. (2020) recognized hunters as people who potentially welcome abundant deer populations, which can also explain their species positive perception.

\subsection{Study limitations}

Our survey was not random, which made that some of the groups were not adequately represented. Our data does not coincide with continental Portugal demography in what refers to gender (in continental Portugal men represented $46.9 \%$ and women $53.1 \%$ in 2013 - INE (2013), while we have $70.6 \%$ responses from men and $29.4 \%$ from women).

Women underrepresentation could result potentially in generally less interest for wildlife (see e.g. Jackson 1993), which was not the case, considering the lack of significance comparing to men and when assessing global results. In what concerns age groups, , although there is not a clear overlap, a certain representativeness is expected (individuals below 30 years - and upper than $15-18.8 \%$ for continental Portugal and $21 \%$ in our work; age group between 30 and 45 years with $25.6 \%$ global and $31.3 \%$ here; individuals between 45 and 60 years with $24.7 \%$ global and $29.6 \%$ here; individuals between 60 and 
75 with $19.3 \%$ global and $15.5 \%$ here; individuals with more than 75 years with $11.6 \%$ global and 2.6\% here (INE 2013)). In Portugal, the number of hunters represent less than $2 \%$ of the population (Massei et al. 2015), however we sampled $>35 \%$. Similarly, farmers represent about $7.1 \%$ of Portuguese population (FFMS 2018), while our survey has about half $(\sim 50 \%)$ of respondent's with this source of income (but only $18 \%$ as a principal source of income, which is however way above country representativeness), that can potentially bias our estimates. Many hunters and farmers participated in our surveys and the participation of the former was particularly high in the survey with the paper questionnaires, since it was mostly aimed to them - however we recognize they can be overrepresented in our sample. The high number of hunters in our survey could have influence our results; e.g. by increasing the general perception of deer benefits, as well as interest in wildlife. However, this could have been compensated somehow with the overrepresentation of farmers' response in the opposite direction (i.e. a low acknowledgement of deer benefits). While it is recognized a link between farmers and the impacts of deer, a direct relation on the overrepresentation of farmers and a general high damage perception cannot be built. The formats of the distribution of the survey (paper copy or online version) could be also a source of bias. Some regions were overrepresented (especially where we collected paper copies of the questionnaire - Figure 1). However, in our brief separate analysis (Appendix C) we did not encounter major contradictions as online, paper, and full models (containing both online and paper version) reported the same tendencies in which concerned differences in sociodemographic data and between interest groups. This lack of difference is noteworthy, since the results with origin in the areas with historical red deer nucleus (paper version), with potentially most 
is no consensus about the impact of distributing the questionnaire online or in paper but our analyses suggest that in our study this was not a major source of bias.

\subsection{Management implications}

371 Although a general positive attitude towards deer was observed, the impacts of red deer and its repercussions asks for a preventive action, and a mitigation strategy whenever necessary. The Spanish case, where ungulate overabundance is already a reality (Acevedo et al. 2008; Carpio et al. 2015), and its socio-ecological consequences fully recognized (Pascual-Rico et al. 2019; Martínez-Jauregui et al. 2020) should be seen as the next step that Portugal will almost inevitably take. With the expected ungulate increase, people's perception will also potentially change, beginning in the regions with red deer historical nucleus (where paper copies were collected), and efforts should be made with priority to these regions. Apart from specific management strategies, several general measures can be taken to mitigate red deer damages. Reduction of deer populations is a practice elsewhere (MacMillan and Leitch 2008; Nugent et al. 2011), and could be a solution, if no management actions are taken, and deer populations continue to rise. If such reduction imposes, we should guarantee that people's opinion, perception and attitudes go towards the cooperation with mitigation measures (Nugent et al. 2011; Martínez-Jauregui et al. 2020), which implies a socio-ecological assessment throughout time and a well-stablished communication strategy, especially directed to young, more qualified individuals and general public whom we identified as the ones with less damage perception.

When these measures cannot balance ecosystem status and damage is still present, compensatory measures to the farmers affected by deer populations (e.g. Novosel et al. 2012) should be considered to minimize conflicts. These results should be seen continuously in a holistic perspective, due to its complexity and easy volatility. 
392 Perceptions change over time, and human dimension of wildlife should serve as an ecological indicator of ecosystem status, given valuables clues of how management measures will be accepted by human populations, which is essential for its success.

\section{Conclusions}

In general, red deer perception is better than expected, however we can see a link between negative attitudes and provoked damages/personal experiences, which will potentially be the trigger that reverses this apparent positive scenario. Hunters showed a positive perception of species, but at the same time they acknowledge deer costs. The need to implement preventive and mitigation measures is independent of these results (considering deer expansion throughout Europe), but is indeed reinforced by them. It is rather essential that general society is fully informed about the consequences of wildlife uncontrolled populations, in order to be aware of the necessity of applying management methods, that are generally unpopular (such as population lethal reduction). Communication strategies targeted, mainly to the general public are essential to ensure the diminish of ungulate related consequences, and thus conflicts. Conflicts are often complex, and its resolution/mitigation should be achieved through multi-disciplinary teams that can give stakeholders the needed information to apply informed and adequate management strategies.

\section{Acknowledgments}

We would also thank to all municipalities, associations and individuals that made possible this work by the answer and spread of our questionnaires and ICNF for providing logistical conditions to perform the study in Bragança. 
417 Ana M. Valente and Ana M. Figueiredo were supported by a PhD grant from Fundação para a Ciência e Tecnologia (SFRH/BD/127817/2016, SFRH/BD/144582/2019 respectively), co-financed by the European Social Fund POPH-QREN program. R. T. Torres is funded by national funds (OE), through FCT - Fundação para a Ciência e Tecnologia, in the scope of the framework contract foreseen in the numbers 4,5 and 6 of the article 23, of the Decree-Law 57/2016, of August 29, changed by Law 57/2017, of July 19. Thanks are due to FCT/MCTES for the financial support to (UIDP/50017/2020+UIDB/50017/2020), through national funds. Pelayo Acevedo thanks to the MINECO grant AGL2016-76358-R and received support from UCLM through an extension of Ramon y Cajal contract (RYC-2012-11970). This paper contributes to the project RTI2018-096348-R-C21/C22 (MCI/AEI/FEDER, UE).

\section{References}

Acevedo, P., Ruiz-Fons, F., Vicente, J., Reyes-García, A. R., Alzaga, V. \&

Gortázar, C. (2008) Estimating red deer abundance in a wide range of management situations in Mediterranean habitats. Journal of Zoology, 276(1), 37-47. DOI: https://doi.org/10.1111/j.1469-7998.2008.00464.x management in the 21st century. UK, Cambridge: Cambridge University Press. 
440 Effectiveness of cattle operated bump gates and exclusion fences in preventing ungulate 441 multi-host sanitary interaction. Preventive veterinary medicine, 111(1-2), 42-50. DOI:

\section{https://doi.org/10.1016/j.prevetmed.2013.03.009}

Behr, D. M., Ozgul, A. \& Cozzi, G. (2017) Combining human acceptance and habitat suitability in a unified socio-ecological suitability model: a case study of the wolf in Switzerland. Journal of Applied Ecology, 54(6), 1919-1929. DOI: https://doi.org/10.1111/1365-2664.12880

Bencatel, J., Sabino-Marques, H., Álvares, F., Moura, A. E. \& Barbosa, A. M. (2019) Atlas de Mamíferos de Portugal. Universidade de Évora, Évora.

Carpio, A. J., Oteros, J., Lora, A. \& Tortosa, F. S. (2015) Effects of the overabundance of wild ungulates on natural grassland in Southern Spain. Agroforestry systems, 89(4), 637-644. DOI: https://doi.org/10.1007/s10457-015-9801-2

Carpio, A. J., Apollonio, M. \& Acevedo, P. (in press) Scenarios of wild ungulates overabundance in Europe: description, causes and management recommendations. Mammal Review

Carvalho, A. M. \& Frazão-Moreira, A. (2011) Importance of local knowledge in plant resources management and conservation in two protected areas from Trás-osMontes, Portugal. Journal of Ethnobiology and Ethnomedicine, 7(1), 36. DOI: https://doi.org/10.1186/1746-4269-7-36

Carvalho, J., Torres, R. T., Acevedo, P., Santos, J. P., Barros, T., Serrano, E. \& Fonseca, C. (2018) Propagule pressure and land cover changes as main drivers of red and roe deer expansion in mainland Portugal. Diversity and Distributions, 24(4), 551-564. DOI: https://doi.org/10.1111/ddi.12703 
López-Bao, J. V., Adamec, M., Álvares, F., Anders, O. \& Balčiauskas, L. (2014)

465

466

467

468

469

470

471

472

473

474

475

476

477

478

479

480

481

482

483

484

Recovery of large carnivores in Europe's modern human-dominated landscapes. Science, 346(6216), 1517-1519. DOI: 10.1126/science.1257553

Côté, S. D., Rooney, T. P., Tremblay, J. P., Dussault, C. \& Waller, D. M. (2004)

Ecological impacts of deer overabundance. Annual Review of Ecology, Evolution, and Systematics,

35 ,

113-147.

DOI:

https://doi.org/10.1146/annurev.ecolsys.35.021103.105725

Delibes-Mateos, M. (2015) Conservation conflicts involving mammals in Europe.

Therya, 6(1), 123-137. DOI: 10.12933/therya-1

Dickman, A. J. (2010) Complexities of conflict: the importance of considering social factors for effectively resolving human-wildlife conflict. Animal conservation, 13(5), 458-466. DOI: https://doi.org/10.1111/j.1469-1795.2010.00368.x

Dickman, A. J. \& Hazzah, L. (2015) Money, Myths and Man-Eaters: Complexities of Human-Wildlife Conflict. In: Angelici FM, editor. Problematic Wildlife: A Cross-Disciplinary Approach, 339-356. Springer, Cham.

Dolman, P., Fuller, R., Gill, R., Hooton, D. \& Tabor, R. (2010) Escalating ecological impacts of deer in lowland woodland. British Wildlife, 21(4), 242.

Driscoll, J. W. (1995) Attitudes toward animals: Species ratings. Society \& Animals, 3(2), 139-150. DOI: https://doi.org/10.1163/156853095X00125

Fox, J. \& Weisberg, S. (2019) An R Companion to Applied Regression. (3rd edition). Sage: Thousand Oaks CA. 
gráficos e indicadores de Municípios, Portugal e Europa. Retrieved May 21, 2020, from

487

http://www.pordata.pt.

Garrido, F. E., Castro, F. \& Villafuerte, R. (2017) Control hunting of wild animals:

health, money, or pleasure?. European journal of wildlife research, 63(6), 95. DOI:

elaphus Linnaeus, 1758) increasing density effects on species assemblage of ground

beetles (Coleoptera: Carabidae) in Alpine forests. European Journal of Wildlife Research,

64(3), 32. DOI: https://doi.org/10.1007/s10344-018-1194-X

Widen, D. \& Acevedo, P. (2012) The status of tuberculosis in European wild mammals.

Mammal Review, 42(3), 193-206. DOI: https://doi.org/10.1111/j.1365-

INE (2013) População residente (N. ${ }^{\circ}$ ) por Local de residência (NUTS - 2002),

500 Sexo e Grupo etário; Anual - INE, Estimativas anuais da população residente. Portal do 501 INE. Retrieved May 21, 2020, from www.ine.pt. 
study for understanding human wildlife conflicts. Biological Conservation, 201, 137-145.

Kellert, S. R. (1983) Affective, cognitive and evaluative perceptions of animals.

In: Altman, I., Wohlwill, J. F. (eds) Behavior and the natural environment. 241-268.

on acceptance capacity for white-tailed deer. The Journal of Wildlife Management, 72(2), 502-509. DOI: https://doi.org/10.2193/2007-117

Human-wildlife conflicts influence attitudes but not necessarily behaviors: Factors driving the poaching of bears in China. Biological Conservation, 144(1), 538-547. DOI: landowner attitudes to deer hunting in the Scottish Highlands. Human ecology, 36(4), 473-484. DOI: https://doi.org/10.1007/s10745-008-9170-9

Madden, F. (2004) Creating coexistence between humans and wildlife: global perspectives on local efforts to address human-wildlife conflict. Human dimensions of wildlife, 9(4), 247-257. DOI: https://doi.org/10.1080/10871200490505675 wild boar (Sus scrofa) populations in Central and Northern Portugal. In Defra \& Fera (eds.), Book of 8th international symposium on wild boar and other suids, (pp.56), York, 
wildlife management: on the diversity of stakeholder attitudes and implications for people: costs, benefits and challenges of living together. Biological Reviews, 95, 782-801.

Addressing social attitudes toward lethal control of wildlife in national parks.

E., Hohmann, U., Monaco, A., Ozoliņš, J. and Cellina, S., (2015) Wild boar populations up, numbers of hunters down? A review of trends and implications for Europe. Pest management science, 71(4), 492-500. DOI: https://doi.org/10.1002/ps.3965

Conservation Biology, 9, 270-278. DOI: https://doi.org/10.1046/j.1523-

548 elaphus) in the Portuguese forests: impacts and new challenges for forest certification.

549 Forest ecology and management, 267, 1-6. 
Mysterud, A. (2004) Temporal variation in the number of car-killed red deer

552 Cervus elaphus in Norway. Wildlife Biology, 10(3), 203-211. DOI:

553

554

555

556

557

558

559

560

561

562

563

564

565

566

567

568

569

570

571

572

573

https://doi.org/10.2981/wlb.2004.026

Newson, S. E., Johnston, A., Renwick, A. R., Baillie, S. R. \& Fuller, R. J. (2012)

Modelling large-scale relationships between changes in woodland deer and bird populations. Journal of Applied Ecology, 49(1), 278-286. DOI:

https://doi.org/10.1111/j.1365-2664.2011.02077.x

Noren, K. E. (2018) Stakeholder attitudes towards and wildlife acceptance capacity for elk (Cervus elaphus) in Kansas (Master dissertation). Kansas State University, Kansas, USA.

Novosel, H., Piria, M., Safner, R., Kutnjak, H. \& Šprem, N. (2012) The game damages on agricultural crops in Croatia. Journal of Central European Agriculture, 13, 631-646. DOI: 10.5513/JCEA01/13.4.1102

Nugent, G., McShea, W. J., Parkes, J., Woodley, S., Waithaka, J., Moro, J., Gutierrez, R., Azorit, C., Guerrero, F.M., Flueck, W. T. \& Smith-Flueck, J. M. (2011) Policies and management of overabundant deer (native or exotic) in protected areas. Animal Production Science, 51(4), 384-389. DOI: https://doi.org/10.1071/AN10288

Pascual-Rico, R., Martín-López, B., Sánchez-Zapata, J. A. \& Morales-Reyes, Z. (2020) Scientific priorities and shepherds' perceptions of ungulate's contributions to people in rewilding landscapes. Science of The Total Environment, 705, 135876. DOI:

\section{https://doi.org/10.1016/j.scitotenv.2019.135876}

Perea, R., Girardello, M. \& San Miguel, A. (2014) Big game or big loss? High deer densities are threatening woody plant diversity and vegetation dynamics. 
574

575

576

577

578

579

580

581

582

583

584

585

586

587

588

589

590

591

592

593

594

595

596

Biodiversity and Conservation, 23, 1303-1318. DOI: https://doi.org/10.1007/s10531$\underline{014-0666-X}$

Peterson, M. N., Birckhead, J. L., Leong, K., Peterson, M. J. \& Peterson, T. R., (2010) Rearticulating the myth of human-wildlife conflict. Conservation Letters, 3, 7482. DOI: https://doi.org/10.1111/j.1755-263X.2010.00099.x

RStudio Team (2015) RStudio: Integrated Development for R. RStudio, Inc., Boston, MA URL http://www.rstudio.com/.

Redpath, S. M., Young, J., Evely, A., Adams, W. M., Sutherland, W. J., Whitehouse, A., Amar, A., Lambert, R. A., Linnell, J. D., Watt, A. and Gutierrez, R. J., (2013) Understanding and managing conservation conflicts. Trends in ecology \& evolution, 28(2), 100-109. DOI: https://doi.org/10.1016/j.tree.2012.08.021

Reimoser, F. \& Reimoser, S. (2010) Ungulates and their management in Austria. European ungulates and their management in the 21st century. Cambridge, UK: Cambridge University Press.

Røskaft, E., Händel, B., Bjerke, T. \& Kaltenborn, B. P. (2007) Human attitudes towards large carnivores in Norway. Wildlife biology, 13(2), 172-186. DOI: https://doi.org/10.2981/0909-6396(2007)13[172:HATLCI]2.0.CO;2

Soga, M. \& Gaston, K. J. (2016) Extinction of experience: the loss of humannature interactions. Frontiers in Ecology and the Environment, 14(2), 94-101. DOI: https://doi.org/10.1002/fee.1225

Storie, J. T. \& Bell, S. (2017) Wildlife management conflicts in rural communities: A case-study of wild boar (Sus scrofa) management in Ērgḷu Novads, Latvia. Sociologia Ruralis, 57(1), 64-86. DOI: https://doi.org/10.1111/soru.12122 

red deer abundance using the pellet-based distance sampling method. Journal of Forest separation of humans from nature. Bioscience, 54(6), 585-590. DOI: of attitudes toward wolves and their reintroduction (1972-2000). Wildlife Society Bulletin, $575-584$.

606

Wittmann, K., Vaske, J. J., Manfredo, M. J. \& Zinn, H. C. (1998) Standards for 607 lethal response to problem urban wildlife. Human Dimensions of Wildlife, 3(4), 29-48. DOI: https://doi.org/10.1080/10871209809359137 species reintroductions: a case study of red deer in Portugal two decades after reintroduction. International Journal of Biodiversity Science, Ecosystem Services \& Management, 13(1), 134-138. DOI: https://doi.org/10.1080/21513732.2016.1277265 consideration of socio-ecological consequences. Mammal Review, 50(2). DOI: 10.1111/mam.12202 
620 their management in Portugal. In Apollonio, M., Anderson, R, Putman, R., European 621 Ungulates and their management in the 21st century. 392-418. Cambridge University 622 Press, Cambridge, UK.

623

624

625

626

627

628

629

630 
632

633

634

635

636

637

638

639

640

641

642

643

644

Figure 1 - Spatial distribution of survey respondent's in the study

area per municipality (continental Portugal) with highlighted

647

municipalities in which paper surveys were collected and red deer

648

(Cervus elaphus) distribution - shown in the top right corner UTM

649

$10 \mathrm{~km}$ x 10km - adapted from Bencantel et al. (2019). 


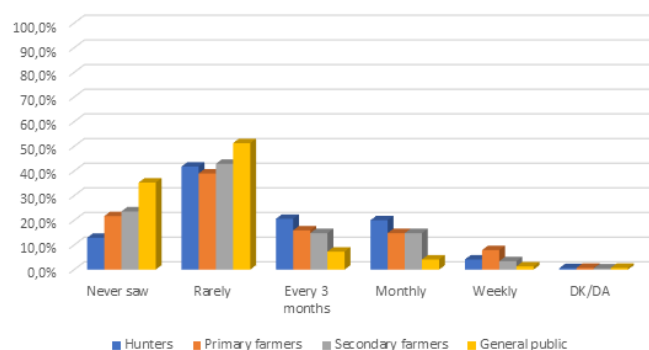

In the last years red deer populations have...

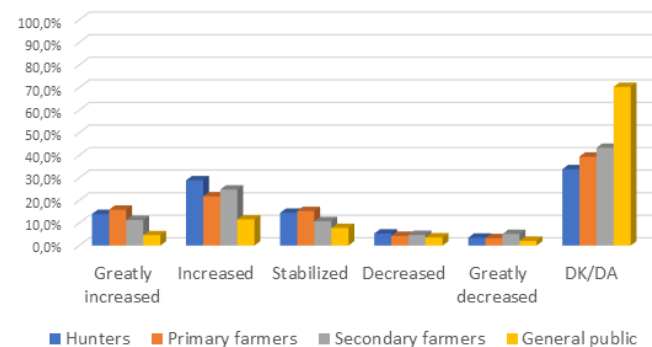

The goal of red deer management should be to their populations.

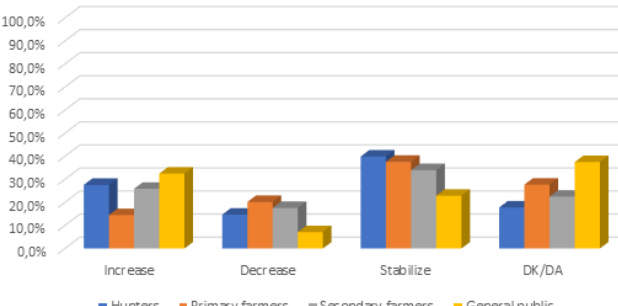

651
How frequently do you see red deer?

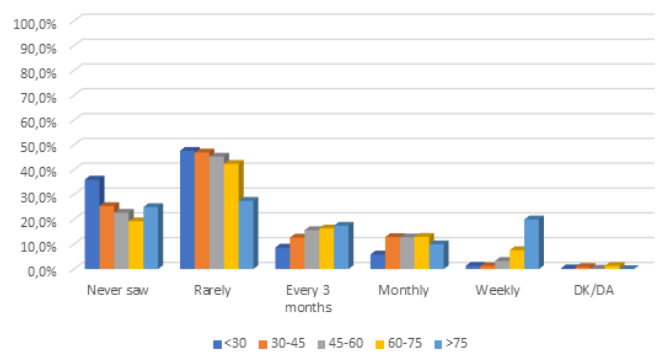

In the last years red deer populations have...

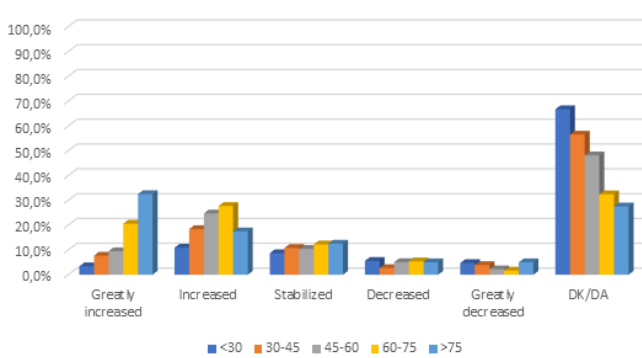

The goal of red deer management should be to

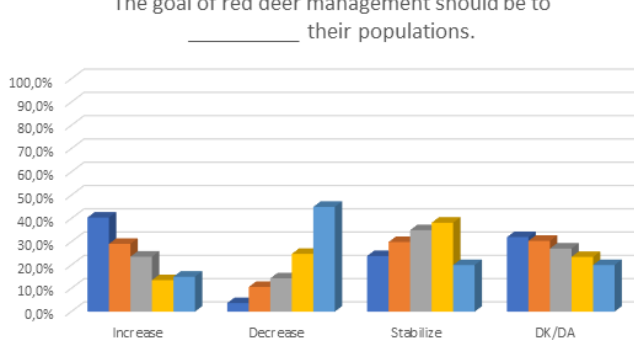

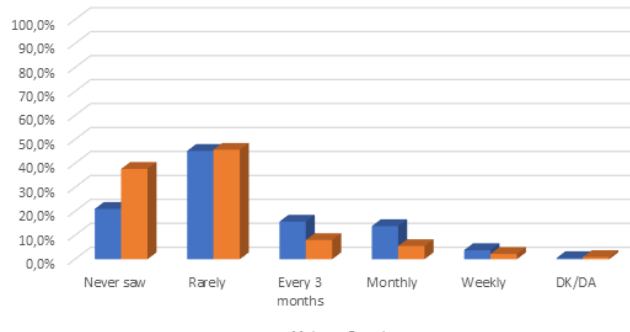

- Male uf fenale

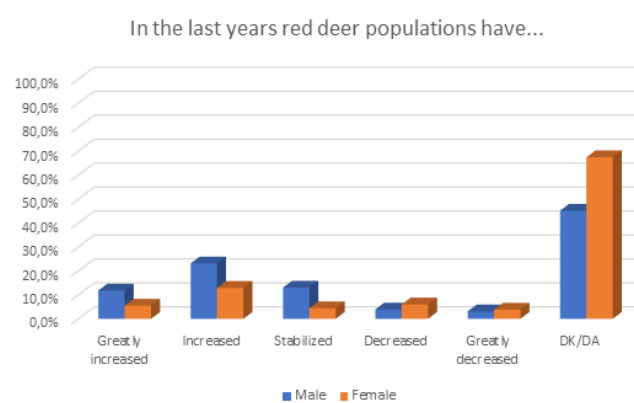

The goal of red deer management shoud be to their populations.

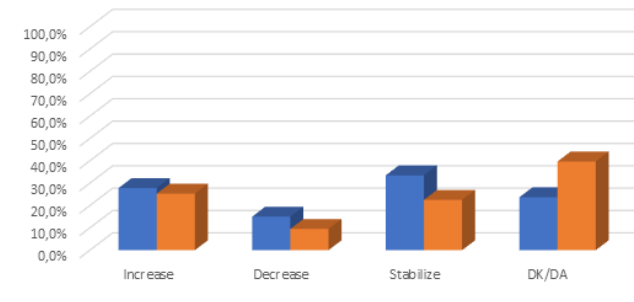

How frequently do you see red deer?

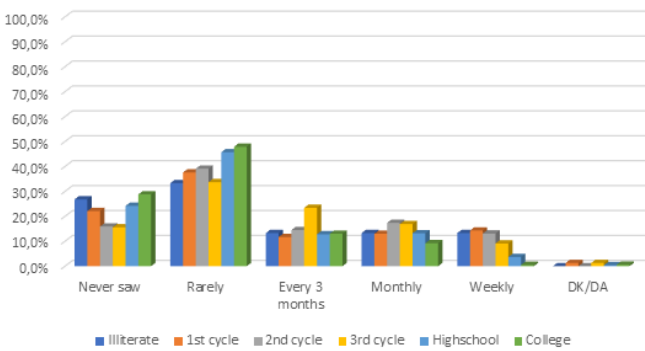

In the last years red deer populations have...

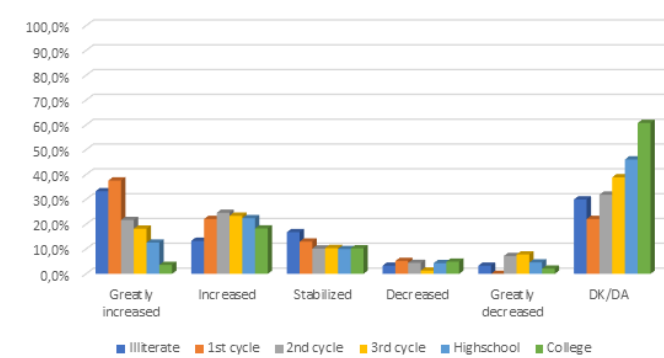

The goal of red deer management should be to their populations

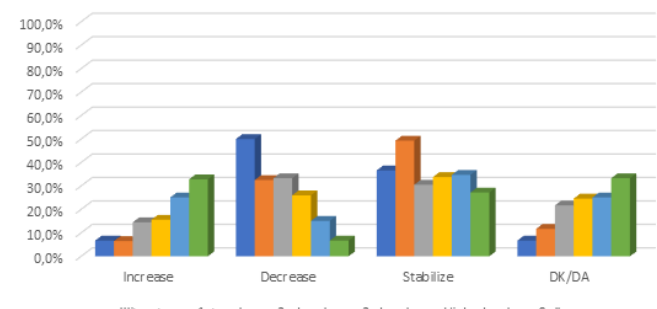

652 how to manage deer populations by interest group, age, gender and academic qualifications. 


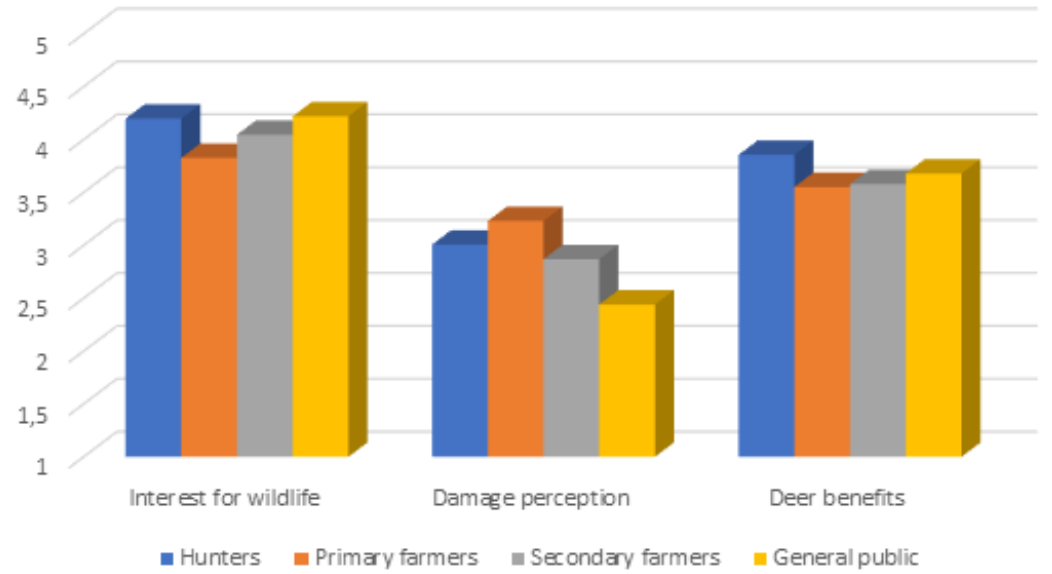

Indexes by gender

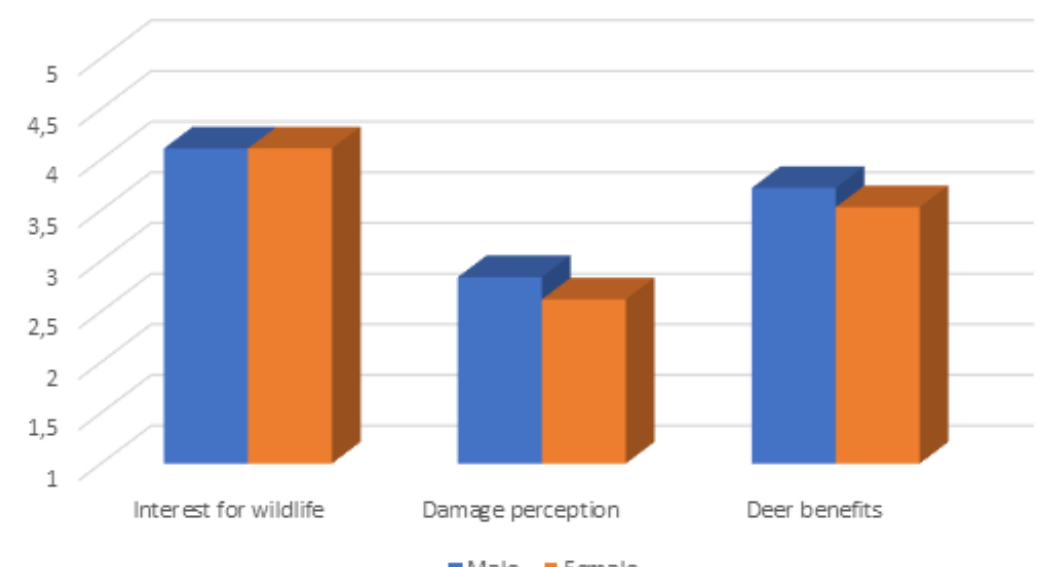

Indexes by academic qualifications

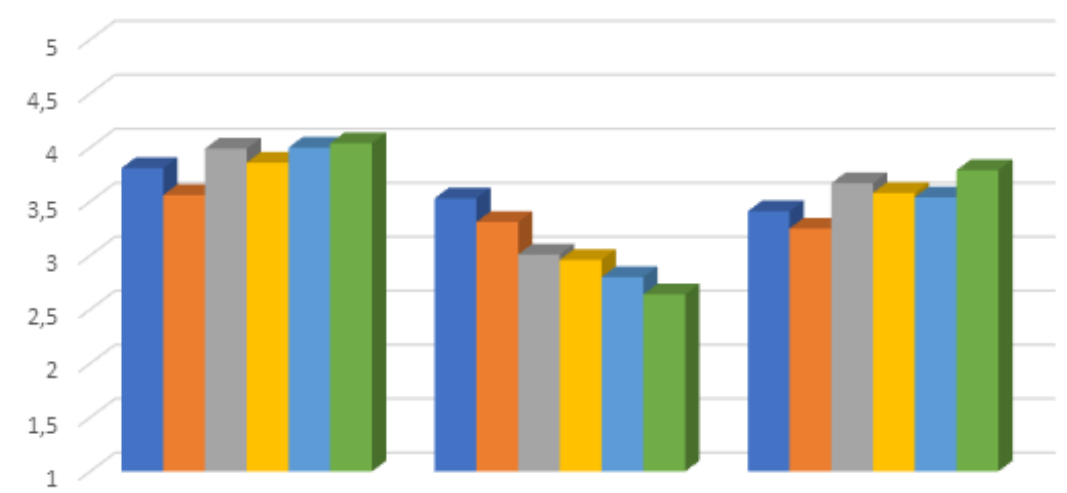

Interest for wildlife

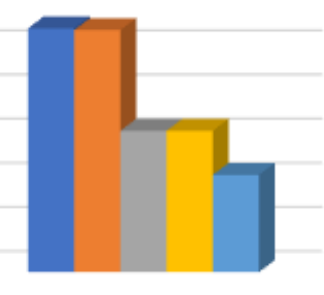

Deer benefits

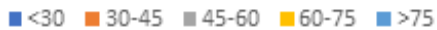

Figure 3 - Interest for wildlife, damage perception and deer benefit indexes by target group, gender, age and academic qualifications. Likert scale from 1 - totally disagree to 5 - totally agree. 
Table 1 - Sociodemographic characterization of survey respondents. AQ Academic qualifications; IG - Interest group.

\begin{tabular}{|lccr|}
\hline Total & $\begin{array}{c}\text { Global } \\
(\mathbf{1 5 3 2})\end{array}$ & $\begin{array}{c}\text { Online } \\
\mathbf{( 1 2 1 9 )}\end{array}$ & $\begin{array}{r}\text { Paper } \\
\mathbf{( 3 1 3 )}\end{array}$ \\
\hline Gender: $\mathrm{M}$ & $\mathbf{7 0 . 6 \%}$ & $69.7 \%$ & $73.8 \%$ \\
\hline Gender: $\mathrm{F}$ & $29.4 \%$ & $30.3 \%$ & $262 \%$ \\
\hline Age: $<30$ & $21.0 \%$ & $23.5 \%$ & $11.2 \%$ \\
\hline Age: $30-45$ & $31.3 \%$ & $34.7 \%$ & $1820 \%$ \\
\hline Age: $45-60$ & $29.6 \%$ & $29.8 \%$ & $28.8 \%$ \\
\hline Age: $60-75$ & $15.5 \%$ & $11.4 \%$ & $31.6 \%$ \\
\hline Age: $>75$ & $2.6 \%$ & $0.6 \%$ & $10.2 \%$ \\
\hline AQ: Illiterate & $2.0 \%$ & $0.1 \%$ & $9.3 \%$ \\
\hline AQ: 1 st cycle & $5.0 \%$ & $0.8 \%$ & $21.4 \%$ \\
\hline AQ: 2nd cycle & $4.5 \%$ & $2.3 \%$ & $13.1 \%$ \\
\hline AQ: 3rd cycle & $5.0 \%$ & $3.5 \%$ & $10.8 \%$ \\
\hline AQ: High school & $28.6 \%$ & $34.7 \%$ & $29.1 \%$ \\
\hline AQ: College & $54.9 \%$ & $29.8 \%$ & $16.3 \%$ \\
\hline IG: Hunters & $35.4 \%$ & $35.6 \%$ & $35.1 \%$ \\
\hline IG: Primary farmers & $18.0 \%$ & $16.5 \%$ & $24.3 \%$ \\
\hline IG: Secondary farmers & $30.7 \%$ & $38.6 \%$ & $362 \%$ \\
\hline IG: General public & $36.7 \%$ & $39.2 \%$ & $27.2 \%$ \\
\hline
\end{tabular}


675 Table 2 - GLM for the six questions after stepwise backwards elimination with the final models, the chosen variables and their p-value.

\begin{tabular}{|c|c|c|c|c|}
\hline Question/Index & Final model & Variables & p-value & 676 \\
\hline \multirow{5}{*}{ Deer sighting frequency } & \multirow{5}{*}{$\begin{array}{c}\sim \text { age }+ \text { gender }+ \text { academic qualifications } \\
+ \text { farming }+ \text { hunting }\end{array}$} & age & 0.002 & \multirow{3}{*}{677} \\
\hline & & gender & 0.017 & \\
\hline & & $\begin{array}{c}\text { academic } \\
\text { qualifications }\end{array}$ & $<0.001$ & \\
\hline & & farmers & $<0.001$ & \\
\hline & & hunters & $<0.001$ & \\
\hline \multirow{2}{*}{$\begin{array}{l}\text { Deer population tendency } \\
\text { perception }\end{array}$} & \multirow{2}{*}{$\sim$ age + gender } & age & $<0.001$ & \\
\hline & & gender & 0.009 & \\
\hline \multirow{2}{*}{ Preferred deer management goal } & \multirow{2}{*}{$\sim$ age + farming } & age & $<0.001$ & \\
\hline & & farmers & $<0.001$ & \\
\hline \multirow{5}{*}{ Interest for wildlife } & \multirow{5}{*}{$\begin{array}{c}\sim \text { age }+ \text { gender }+ \text { academic qualifications } \\
+ \text { farming }+ \text { hunting }\end{array}$} & age & $<0.001$ & \\
\hline & & gender & 0.56 & \\
\hline & & $\begin{array}{c}\text { academic } \\
\text { qualifications }\end{array}$ & $<0.001$ & \\
\hline & & farmers & $<0.001$ & \\
\hline & & hunters & $<0.001$ & \\
\hline \multirow{4}{*}{ Damage perception } & \multirow{4}{*}{$\begin{array}{c}\sim \text { age }+ \text { academic qualifications }+ \text { farming } \\
+ \text { hunting }\end{array}$} & age & $<0.001$ & \\
\hline & & $\begin{array}{c}\text { academic } \\
\text { qualifications }\end{array}$ & $<0.001$ & \\
\hline & & farmers & $<0.001$ & \\
\hline & & hunters & $<0.001$ & \\
\hline \multirow{5}{*}{ Deer benefits } & \multirow{5}{*}{$\begin{array}{c}\sim \text { age }+ \text { gender }+ \text { academic qualifications } \\
+ \text { farming }+ \text { hunting }\end{array}$} & age & $<0.001$ & \\
\hline & & gender & 0.007 & \\
\hline & & $\begin{array}{c}\text { academic } \\
\text { qualifications }\end{array}$ & $<0.001$ & \\
\hline & & farmers & $<0.001$ & \\
\hline & & hunters & $<0.001$ & \\
\hline
\end{tabular}

